\title{
The Chronic Sick in the Final Phase of his Illness in Intensive Care Requires the Transition of Healing a Palliative Care
}

\author{
Rubén D Camargo \\ Internal Medicine, Intensive Care, Bioethic, \\ Columbia
}

\section{Corresponding author:}

Rubén D Camargo

\section{Abstract}

It is important to differentiate patients with Chronic non-communicable diseases (NCD), in the final phase of his illness, from the chronic critically ill (CCI) in intensive care, all this patient are benefiting of care until the end of life, this being palliative care.

Palliative care, known in some parts as "control group of symptoms the transition from curative to palliative care in the patient in the final stages of a terminal disease, chronic non-communicable disease or $\mathrm{CCl}$ are often imperceptible.

Keywords: Chronic critically ill; Palliative care; Final phase

Received: December 28, 2015; Accepted: January 08, 2016; Published: January 15, 2016

\section{Critical Care III Patients and Chronic Patients}

The admission of patients in Intensive Care Units it is aimed at therapeutic support, monitoring and critical care. Only when these fail the clinical group caring for the patient should consider rethinking its objectives to the patient and family face. This change is called transition, which is one of the most difficult and important aspects of critical care, for Intensivist as nurse in medical practice in intensive care. But what kind of patients are?

This increased incidence of chronic disease (NCD) is one of the most important challenges for the health system. The most important according to the World Health Organization, CVD is the leading cause of death worldwide. Age, especially for people aged 65 years or older, increases the risks associated with heart disease or heart attacks [1-3].

One Medical group had demonstrated the feasibility of incorporating care managers (specially trained nurses) into the health care system to support General practitioners (GPs) and specialists in the management of patients with chronic noncommunicable diseases NCD specialty CVD, diabetes, heart failure, or CVD risk. Care managers worked directly with individual patients, helping them to make lifestyle changes. This kind of work may be helping to minimize the admission of patients with chronic disease NCD in Intensive care with CVD [4].

The rate of hospitalizations for decompensated chronic conditions; Chronic non-communicable diseases (NCD), as cardiovascular disease CVD (heart attacks and stroke), cancer, chronic respiratory diseases (such as chronic obstructive pulmonary disease and asthma) diabetes and amyotrophic lateral sclerosis (ALS) among older people is higher in intensive care units [5].

Many critically ill patients survive their initial acute illness but go on to experience persistent organ failures necessitating prolonged intensive care a syndrome known as chronic critical illness (CCl) [6]. The most common eligible conditions are acute respiratory failure requiring mechanical ventilation and sepsis. The sepsis cases are related to infections acquired in the hospital. This finding does not necessary imply that hospitalacquired infection directly cause of $\mathrm{CCl}$ [7] these conditions are characterized by to prolonged organ failures, neuromuscular weakness, and neurocognitive dysfunction; all of which are the hallmarks of $\mathrm{CCl}$. The prevention will be the early treatment of sepsis and acute respiratory failure is an important target for $\mathrm{CCl}$ prevention. Feature of this group is its prolonged dependence on mechanical ventilation ( $7 \%$ to $15 \%$ ) in the intensive care unit [8].

Although the prevalence of $\mathrm{CCl}$ generally rises with age, it declines after 80 years, because this kind of patients dies before day 8 in an $\mathrm{UCl}$. However, given that the vast majority of ICU deaths are preceded by a decision to withdraw or withhold life support, in terminal patients.

Terminally ill patient is a medical term indicating that a disease cannot be cured or treated properly, and is expected as a result the patient's death within a short time. This term is most commonly used for degenerative diseases such as cancer, or 
advanced heart or lung disease. This expression became popular in the twentieth century, to indicate a disease that will eventually end with a person's life.

The Palliative care may be difficult in intensive care units, where patients with Chronic NCD or CCl are not separated from the beds of the area. The transition must occur in a smooth manner with reference to the needs, patient diagnosis and family situation [9].
Powers distinguish the transition from curative care to palliative care; private, quiet, without technology or alarms spaces. Will result in better care for serious chronic and critical chronic phase of a terminal illness and help the development of institutional policies to guide decision-making at the end of life involving the family and support team (religious, social workers, psychologists, etc.) [10] 


\section{References}

1 Angus DC, Barnato AE, Linde-Zwirble WT, Weissfeld LA, Watson RS, et al. (2004) Use of intensive care at the end of life in the United States: An epidemiologic Study. Crit Care Med 32: 638-643.

2 Lynn E, Chaudhary LN, Simon AM, Wilkinson JL (2007) The common sense guide to Improving Palliative Care J. Schuster - Trajectories of illness: matching the care system to how people die. Oxford, United Kingdom.

3 Davies E, Higgins I (2004) Better Palliative Care for Older People. World Health Organization, Geneva, Switzerland.

4 Marco MC, Ambrogio A, Pietro S, Marco S, Ernesto M, et al. (2010) Feasibility and effectiveness of a disease and care management model in the primary health care system for patients with heart failure and diabetes (Project Leonardo). Vascular Health and Risk Management 6: 297-305.

5 Nelson JE, Cox CE, Hope AA, Carson SS (2010) Chronic critical illness. Am J Respir Crit Care Med 182: 446-454.
6 Kahn JM, Le T, Angus DC, Cox CE, Hough CL, et al. (2015) The epidemiology of chronic critical illness in the United States.Crit Care Med 43: 282-287.

7 Burgmann H, Hiesmayr JM, Savey A, Bauer P, Metnitz B, et al. (2010) Impact of nosocomial infections on clinical outcome and resource comsumption in crtically ill patients. Intensive Care Med 36: 15971601.

8 Villar J, BlancoJ, Zhang H, Slutsky AS (2011) Ventilator-induced lung injury and sepsis. Two sides of the same coiun? Minerva Anestesiol 77: 647-653.

9 Nelson JE, Bassett R, Boss RD, Brasel KJ, Campbell ML, et al. (2010) Models for structuring a clinical initiative to enhance palliative care unit for the improve Palliative Care in the intensive care Unit Project. Crit Care Med 38: 1765-1772.

10 Lim SS, Vos T, Flaxman AD, Danaei G, Shibuya K, et al. (2012) A comparative risk assessment of burden of disease and injury attributable to 67 risk factors and risk factor clusters in 21 regions, 1990-2010: a systematic analysis for the Global Burden of Disease Study 2010. Lancet 380: 2224-2260. 